\title{
Social anxiety symptoms in alcohol-dependent outpatients: prevalence, severity and predictors
}

\author{
Sintomas de ansiedade social em alcoolistas em tratamento \\ ambulatorial: prevalência, gravidade e preditores \\ Nicoli Tamie Yoshimi', Luana Moraes Campos', Maria Odete Simão², Ricardo Cezar Torresan², \\ Albina Rodrigues Torres²
}

\section{ABSTRACT}

Objectives: High rates of comorbidity between social anxiety disorder (SAD) and alcohol use disorders have been reported, but the predictors of this comorbidity are poorly known and most studies involve primary SAD samples. The aims were to estimate the prevalence and severity of SAD symptoms among alcohol-dependent patients and to investigate sociodemographic and clinical factors associated with SAD comorbidity, including suicidal behaviors. Methods: A cross-sectional study with 53 adults who were in treatment for alcohol dependence at a Brazilian public university outpatient service. Assessment instruments: Social Phobia Inventory (SPIN), Short Alcohol Dependence Data and Beck Depression Inventory. Bivariate analyses between the categorical outcome (Probable SAD: SPIN $\geq 19$ ) and explanatory variables were conducted. Correlates of SPIN total and subscales scores (dimensional outcomes) were also investigated. Results: The diagnosis and treatment of alcohol dependence occurred, on average, 30 years after the onset of alcohol use and 39.6\% of the 53 patients (37 men and 16 women) reported alleviation of social anxiety symptoms with alcohol use. Twenty-four (45.3\%) patients presented probable SAD. These patients differed from non-SAD alcohol-dependent individuals by having lower income and higher frequency of depression, suicidal ideation, suicide plans and attempts. The SPIN subscales

\section{Keywords}

Social anxiety disorder, social phobia, alcohol dependence, alcohol use disorders, comorbidity. mostly associated with suicidal behaviors were social inadequacy and social inferiority. Conclusions: SAD symptoms are common among help-seeking alcohol-dependent individuals and should be directly investigated and treated, since depression and suicidality are associated with this comorbidity. Prospective studies are needed to assess the impact of SAD treatment on the clinical course of alcohol dependence.

\section{RESUMO}

Objetivos: Altas taxas de comorbidade têm sido descritas entre o transtorno de ansiedade social (TAS) e os transtornos por uso de álcool, mas os preditores dessa comorbidade são pouco conhecidos, e a maioria dos estudos envolve pacientes com diagnóstico primário de TAS. Os objetivos foram estimar a prevalência e a gravidade de sintomas de TAS em pacientes dependentes de álcool e investigar fatores sociodemográficos e clínicos associados

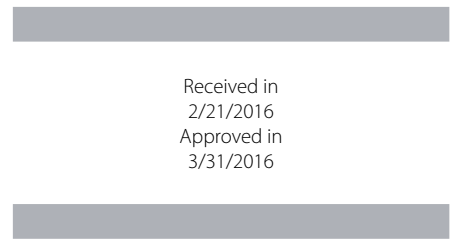

DOI: $10.1590 / 0047-2085000000112$
1 Sao Paulo State University (Unesp), Botucatu Medical School (FMB).

2 Unesp-FMB, Department of Neurology, Psychology and Psychiatry.

Address for correspondence: Albina Rodrigues Torres

Departamento de Neurologia, Psicologia e Psiquiatria

Faculdade de Medicina de Botucatu (FMB), Universidade Estadual Paulista (Unesp)

Av. Prof. Montenegro, s/n, Distrito de Rubião Jr.

18618-970 - Botucatu, SP, Brazil

Telephone: (55 14) 3880-1220

E-mails: torresar@fmb.unesp.br or albinatorres@gmail.com 


\author{
Palavras-chave \\ Transtorno de ansiedade \\ social, fobia social, \\ dependência de álcool, \\ transtornos por uso de \\ álcool, comorbidade.
}

à comorbidade com TAS, incluindo risco de suicídio. Métodos: Estudo transversal com 53 adultos em tratamento ambulatorial para dependência de álcool num hospital público universitário brasileiro. Instrumentos de avaliação: Social Phobia Inventory (SPIN), Short Alcohol Dependence Data e Beck Depression Inventory. Foram conduzidas análises bivariadas entre o desfecho categorial (provável TAS: SPIN $\geq 19$ ) e as variáveis explanatórias. Correlatos dos escores total e das subescalas da SPIN (desfechos dimensionais) também foram investigados.

Resultados: $O$ diagnóstico e o tratamento da dependência de álcool ocorreram em média 30 anos após o início do uso de álcool, e 39,6\% dos 53 pacientes (37 homens e 16 mulheres) relataram alívio dos sintomas de ansiedade social com o uso de álcool. Vinte e quatro $(45,3 \%)$ pacientes apresentaram provável TAS. Esses pacientes diferiram dos alcoolistas sem TAS, por terem menor renda, maior frequência de depressão, ideação suicida, planos e tentativas de suicídio. As subescalas da SPIN que mais se associaram com comportamentos suicidas foram inadequação social e inferioridade social. Conclusões: Sintomas de TAS são comuns em alcoolistas em tratamento e devem ser diretamente investigados e tratados, já que depressão e suicidalidade associam-se com essa comorbidade. Estudos prospectivos são necessários para investigar o impacto do tratamento do TAS no curso clínico da dependência de álcool.

\section{INTRODUCTION}

Social anxiety disorder (SAD) is characterized by an excessive fear and avoidance of social situations in which the individual believes his/her performance may be negatively evaluated by others'. The mean age of SAD onset is 13 years and, in $75 \%$ of the cases, it begins between the ages of eight and 15 years' ${ }^{1}$. The prevalence rates of SAD in community studies were estimated in 1.9\% (annual) and 2.8\% (lifetime) ${ }^{2}, 5.0 \%$ (lifetime) $^{3}, 6.8 \%$ (annual) $^{4}$ and $12.0 \%$ (lifetime) $^{5}$. In Brazil, only two epidemiological surveys were conducted, both in São Paulo city, and the annual and lifetime prevalence rates were $2.2 \%{ }^{6}$ and $3.9 \%$, respectively ${ }^{7}$.

Previous studies demonstrated high rates of comorbid alcohol use disorders (AUD) among anxiety disorder patients in general $\left.\right|^{8-12}$ and SAD patients in particular ${ }^{13}$. Some individuals with $S A D$ use alcohol recurrently to reduce the anxiety, tension and inhibition they feel in social situations, developing secondary dependence ${ }^{13,14}$. However, the diagnosis of SAD in alcohol-dependent patients may be hampered by its clinical similarity with withdrawal symptoms (e.g. anxiety, tremors, sweating, increased heart rate) $)^{8,15}$ and by the fact that some persons with AUD may develop social anxiety symptoms due to the shame of their behaviors while intoxicated ${ }^{16}$. In anxiety disorders, the comorbidity with AUD has great clinical relevance, as it implies a worse prognosis, including poor treatment response and increased suicide risk ${ }^{8,17}$. To date, only a few studies explored the prevalence of SAD among individuals seeking treatment for alcohol dependence, and the rates described vary from $23 \%$ to $35 \% 15,18-20$. In two studies that included outpatients with alcohol and illicit drugs dependence the prevalence rates of SAD were also high: $31 \%{ }^{21}$ and $37 \%{ }^{22}$.

Among patients who seek treatment for AUD, those with SAD present more severe dependence, more depressive episodes, less social support, lower education and worse occupational situation ${ }^{18,23}$. Moreover, SAD comorbidity may have a negative impact on the willingness to participate in addiction treatments - which frequently include group therapies ${ }^{22}$ - and also on treatment outcomes ${ }^{24}$. Therefore, if not identified and properly treated, SAD can have a negative impact on the prognosis of alcohol dependence, favouring relapses ${ }^{8,12}$. Although clinically relevant, the literature on prevalence and predictors of SAD comorbidity among alcohol-dependent patients is very scarce. In Brazil, only two studies on this topic were conducted, with hospitalized patients ${ }^{15,20}$.

The aims of this study were to estimate the prevalence and severity of SAD symptoms among alcohol-dependent outpatients and to investigate sociodemographic and clinical factors associated with SAD comorbidity, including suicidal behaviors. An additional aim was to evaluate the severity and correlates of specific SAD symptoms in this population.

\section{METHODS}

\section{Subjects}

A cross-sectional study was conducted with 53 consecutive adult patients (men and women) undergoing outpatient treatment for alcohol dependence at a Brazilian public university hospital (Unesp-FMB). The inclusion criteria were: being 18 years or older, being in outpatient treatment for alcohol dependence - diagnosed according to the DSM-IV criteria ${ }^{25}$ - and agreeing to participate in the study, after being fully advised about its objectives and methods. Participants received no financial compensation. There were no refusals and all participants signed an informed consent form. The study was approved by the FMB Research Ethics Committee in May 2013 (protocol number 264.098). 


\section{Procedures and assessment instruments}

Patients were interviewed between May/2013 and June/2014 by two trained undergraduate medical students (NTY and $\mathrm{CML}$ ), in the same day of the patients' regular appointment at the outpatient unit. Patients were considered currently abstinent when not using alcohol for at least 30 days, and intoxicated patients were not interviewed. Since most participants had low educational level, the measures were not used as self-report, but as face-to-face interviews. The protocol included a questionnaire on sociodemographic (gender, age, educational level, ethnicity, religion, marital and occupational status and income) and clinical data (age of onset of alcohol use, age at diagnosis and first treatment for alcohol dependence, family history of alcohol dependence, current abstinence, previous relapses and hospitalizations for alcohol dependence, use of tobacco, cannabis and other illicit drugs, alcohol effect on SAD symptoms and suicidal behaviors). The questions on suicidality were adapted from the Clinical Interview Schedule-Revised (CIS-R) ${ }^{26,27}$, consisting of direct questions with dichotomous answers (yes/no) asking if the patient had ever thought that life was not worth living, wished to be dead, thought about killing himself/herself, made suicidal plans, attempted suicide or presented current suicidal thoughts. Those who reported current suicidal ideation were evaluated in the same day by the psychiatrist responsible for the alcohol dependence service (RCT). The structured instruments that were applied to the participants by the interviewers are described below:

The Social Phobia Inventory - SPIN28: SAD symptoms were assessed using the SPIN, which was translated and adapted into Brazilian Portuguese ${ }^{29}$. The Brazilian version was validated $^{30}$ and presents adequate psychometric properties, including good internal consistency and reliability ${ }^{31,32}$. It consists of 17 items that investigate anxiety, physical discomfort and avoidant behaviors in several social situations in the previous week. Each item has a score ranging from 0 to 4 (maximum: 68). The cutoff point of 19 or more indicates the presence of symptoms suggestive of SAD 32,33 . The scale has five subscales, which severity can be assessed separately22: social inadequacy (range: 0-16), self-esteem (range: 0-16), physical symptoms (range: 0-16), social inferiority (range: 0-8) and performance when observed by others (range: 0-12). The predictors of SPIN total and subscales scores (quantitative outcomes) were also analyzed.

The Short Alcohol Dependence Data (SADD) ${ }^{34}$ : The SADD consists of 15 questions investigating dependence current severity in cases of alcohol use disorder. Each question has four options, defined as: 0 - never, 1 - rarely, 2 - often, 3 - always. The overall score indicates the following classification: 1-9 - mild dependence, 10-19 - moderate dependence, 20-45 - severe dependence ${ }^{34-36}$. The adopted cutoff score for moderate or severe dependence was 10 .
Beck Depression Inventory $(\mathrm{BDI})^{37}$ : The $\mathrm{BDI}$ consists of 21 items that assess depressive symptoms in the previous week, and the severity ranges from zero to three (maximum: 63). The following cutoff points are recommended: $<10$ - no depression; 10-18 - mild depression; 19-29 - moderate depression and 30-63 - severe depression ${ }^{37}$. The cutoff point of 19 or more was considered indicative of (moderate or severe) depression.

\section{Data analysis}

The STATA 12.0 software ${ }^{38}$ was used in all statistical analyses. Initially, a descriptive analysis of all explanatory variables was conducted, to estimate absolute and relative frequencies of the categorical variables and central distribution measures (means and standard deviations, medians and ranges) of the quantitative variables. The outcome was first analyzed as a dichotomous variable (Probable SAD: SPIN score $\geq 19$ ), and the prevalence with 95\% confidence interval was estimated. The patients were then divided into two comparison groups: Probable SAD Group and Non-SAD Group. Bivariate analyses of the associations between the outcome (Probable SAD) and explanatory variables were conducted using the Pearson Chi-square or Fisher's exact tests (categorical variables) and the Student t or Mann-Whitney tests (quantitative variables), as appropriate. The normality of distribution of the quantitative variables was evaluated with the Skewness and Kurtosis test. To estimate the effect sizes of the associations, odds ratios with 95\% confidence intervals were calculated for categorical variables and Cohen's D for quantitative variables (values lower than 0.3 generally indicate little effect, 0.3 to 0.5 moderate effect, and above 0.5 relevant effect). Finally, the outcome was analyzed as a quantitative variable (SPIN total score and five subscales scores) in relation to the same explanatory variables, using the Mann-Whitney test for categorical variables and the Spearman's correlation test for quantitative variables. Statistical significance was defined as $p<0.05$.

\section{RESULTS}

\section{Sociodemographic and clinical characteristics of the sample}

The mean age of the 53 patients was 49.6 (SD 12.01) years old, $37(69.8 \%)$ were males and 16 (30.2\%) females. Most patients (71.2\%; $n=39)$ were Caucasian, $60.4 \%$ were married or cohabiting, $67.9 \%$ were Catholic (only one patient had no religion) and $50.9 \%$ were currently working. The mean number of years of formal education was 8.43 (4.4) and $64.8 \%$ had low educational level, i.e., less than eight years of schooling (Table 1).

The mean age of onset of alcohol use was 16.4 (7.1) years, whereas the mean ages of diagnosis and first treatment for alcohol dependence were 43.8 (11.6) and 44.9 (12.1) years, respectively. Almost all patients were abstinent (no alcohol use for at least 30 days) at the time of interview (94.3\%) and re- 
Table 1. Sociodemographic characteristics of the sample, according to social anxiety disorder (SAD) comorbidity

\begin{tabular}{|c|c|c|c|c|c|c|c|c|}
\hline Sociodemographic characteristics & \multicolumn{2}{|c|}{ Total $(n=53)$} & \multicolumn{2}{|c|}{$\operatorname{SAD}(n=24)$} & \multicolumn{2}{|c|}{ Non-SAD $(n=29)$} & p-value & Effect size \\
\hline Quantitative variables & \multicolumn{2}{|c|}{ Mean (SD) } & \multicolumn{2}{|c|}{ Mean (SD) } & \multicolumn{2}{|c|}{ Mean (SD) } & $\mathrm{p}$ & Cohen's D \\
\hline Age (years) & \multicolumn{2}{|c|}{$49.64(12.01)$} & \multicolumn{2}{|c|}{$46.16(9.23)$} & \multicolumn{2}{|c|}{$52.52(13.38)$} & $0.054^{\mathrm{a}}$ & 0.52 \\
\hline Income (Brazilian real) & \multicolumn{2}{|c|}{$1647(1875)$} & \multicolumn{2}{|c|}{$814(514)$} & \multicolumn{2}{|c|}{$2307(227)$} & $0.003^{b}$ & 0.79 \\
\hline Educational level (years) & \multicolumn{2}{|c|}{$8.43(4.40)$} & \multicolumn{2}{|c|}{$8.12(4.08)$} & \multicolumn{2}{|c|}{$8.69(4.70)$} & $0.62^{\mathrm{a}}$ & 0.12 \\
\hline Categorical variables & $\mathrm{n}$ & $\%$ & $n$ & $\%$ & $\mathrm{n}$ & $\%$ & $\mathrm{p}$ & OR (C $195 \%)$ \\
\hline Sex & & & & & & & $0.29^{c}$ & \\
\hline Female & 16 & 30.2 & 9 & 56.2 & 7 & 43.8 & & 1 \\
\hline Male & 37 & 69.8 & 15 & 40.5 & 22 & 59.5 & & $0.53(0.16-1.73)$ \\
\hline Ethnicity & & & & & & & $0.46^{c}$ & \\
\hline Caucasian & 38 & 71.7 & 16 & 42.1 & 22 & 57.9 & & 1 \\
\hline Non-caucasian & 15 & 28.3 & 08 & 53.3 & 07 & 46.7 & & $1.17(0.55-2.49)$ \\
\hline Marital status & & & & & & & $0.78^{c}$ & \\
\hline With partner & 32 & 60.4 & 14 & 43.7 & 18 & 56.3 & & 1 \\
\hline No partner & 21 & 39.6 & 10 & 47.6 & 11 & 52.4 & & $1.17(0.64-2.12)$ \\
\hline Religion & & & & & & & $0.17^{c}$ & \\
\hline Catholic & 35 & 66.0 & 14 & 38.9 & 22 & 61.1 & & 1 \\
\hline Non-catholic & 18 & 34.0 & 10 & 58.8 & 7 & 41.2 & & $2.24(0.69-7.27)$ \\
\hline Low educational level* & & & & & & & $0.13^{c}$ & \\
\hline No & 19 & 35.9 & 6 & 31.6 & 13 & 68.4 & & 1 \\
\hline Yes & 34 & 64.1 & 18 & 52.9 & 16 & 47.1 & & $2.44(0.75-7.92)$ \\
\hline Currently working & & & & & & & $0.13^{c}$ & \\
\hline Yes & 27 & 50.9 & 15 & 55.6 & 12 & 44.4 & & 1 \\
\hline No & 26 & 49.1 & 9 & 34.6 & 17 & 65.5 & & $2.36(0.78-7.15)$ \\
\hline
\end{tabular}

a Student t test; ${ }^{\mathrm{b}}$ Mann-Whitney test; ' ${ }^{\mathrm{C}}$ Chi-square test; ${ }^{\mathrm{d}}$ Fisher's exact test.

SAD: social anxiety disorder; SD: standard deviation.

* Less than 8 years of schooling.

ported family history of alcohol dependence (92.4\%), whereas one third reported at least one previous psychiatric hospitalization. The duration of abstinence varied widely, from one week to 10 years (median: 24 weeks). The mean SADD score was 3.52 (5.48) and only five patients (9.4\%) presented moderate or severe alcohol dependence at the time of interview. The mean BDI score was 12.3 (11.6) and 12 patients (22.6\%) presented moderate or severe depressive symptoms.

Current and previous tobacco smoking was reported by $43.4 \%$ and $26.4 \%$ of the patients, respectively. Regarding cannabis use, $22.6 \%$ reported previous use and all denied current use. Lifetime use of other illicit drugs (excluding cannabis) was reported by $15.1 \%$ and only one patient reported current use. While $39.6 \%$ of the patients reported a decrease of SAD symptoms with the alcohol use, $47.2 \%$ denied any effect and 13.2\% reported aggravation. With respect to suicidal behaviors, lifetime thoughts, plans and attempts were described by $58.5 \%$, $41.5 \%$ and $39.6 \%$, respectively, and current thoughts by $9.4 \%$.

The prevalence of probable SAD (SPIN score $\geq 19$, from now on just called SAD) was $45.3 \%$ (95\% Cl: 31.4 to 59.1\%).
The SPIN average score was 20.3, ranging from 0 to 68 . The mean (SD) total and subscales scores of the SPIN were: social inadequacy 3.94 (4.11), self-esteem 5.62 (5.17), physiological symptoms 4.87 (5.00), social inferiority 0.81 (1.92) and performance when observed by others 5.09 (3.95). Other clinical characteristics are presented in table 2 .

\section{Sociodemographic and clinical characteristics of the sample, according to the presence (or absence) of probable social anxiety disorder (SAD)}

The only sociodemographic variable that differed significantly between the two study groups was income, in average lower in patients presenting SAD (Table 1). Moderate or severe depression (OR 5.20), suicidal ideation (OR 3.69), suicide plans (OR 5.24) and attempts (OR 4.40) were more frequent in patients with SAD. The mean BDI score (depressive symptoms) was also higher in the group with SAD. The other clinical variables did not differ significantly between the study groups, as presented in table 2 . 
Table 2. Clinical characteristics of the sample, according to social anxiety disorder (SAD) comorbidity

\begin{tabular}{|c|c|c|c|c|c|c|c|c|}
\hline Clinical characteristics & \multicolumn{2}{|c|}{ Total $(n=53)$} & \multicolumn{2}{|c|}{ Probable SAD $(n=24)$} & \multicolumn{2}{|c|}{ Non-SAD $(n=29)$} & p-value & Effect size \\
\hline Quantitative variables & \multicolumn{2}{|c|}{ Mean (SD) } & \multicolumn{2}{|c|}{ Mean (SD) } & \multicolumn{2}{|c|}{ Mean (SD) } & p & Cohen's D \\
\hline Age onset - Alcohol use & \multicolumn{2}{|c|}{$16.41(7.08)$} & \multicolumn{2}{|c|}{$16.25(9.36)$} & \multicolumn{2}{|c|}{$16.55(4.60)$} & $0.20^{\mathrm{a}}$ & 0.04 \\
\hline Age of diagnosis & \multicolumn{2}{|c|}{$43.77(11.64)$} & \multicolumn{2}{|c|}{$42.41(8.54)$} & \multicolumn{2}{|c|}{$44.90(13.74)$} & $0.73^{\mathrm{a}}$ & 0.21 \\
\hline Age of first treatment & \multicolumn{2}{|c|}{$44.87(12.11)$} & \multicolumn{2}{|c|}{$42.46(8.60)$} & \multicolumn{2}{|c|}{$46.86(14.23)$} & $0.30^{\mathrm{a}}$ & 0.36 \\
\hline BDI score & \multicolumn{2}{|c|}{$12.35(11.67)$} & \multicolumn{2}{|c|}{$18.42(12.22)$} & \multicolumn{2}{|c|}{$7.34(8.53)$} & $<0.001^{\mathrm{a}}$ & 0.94 \\
\hline SADD score & \multicolumn{2}{|c|}{$3.52(5.53)$} & \multicolumn{2}{|c|}{$4.67(7.18)$} & & & $0.22^{\mathrm{a}}$ & 0.37 \\
\hline Categorical variables & $n$ & $\%$ & $n$ & $\%$ & $\mathrm{n}$ & $\%$ & $p$ & OR (C 95\%) \\
\hline Family history (alcoholism) & & & & & & & $0.62^{b}$ & \\
\hline No & 4 & 7.5 & 01 & 25.0 & 03 & 75.0 & & 1 \\
\hline Yes & 49 & 92.5 & 23 & 46.9 & 26 & 53.1 & & $2.65(0.26-27.32)$ \\
\hline Abstinence (current) & & & & & & & $1.00^{b}$ & \\
\hline Yes & 50 & 94.3 & 23 & 46.0 & 27 & 54.0 & & 1 \\
\hline No & 3 & 5.7 & 01 & 33.3 & 02 & 66.7 & & $1.70(0.14-20.0)$ \\
\hline Relapse (previous) & & & & & & & $0.17^{c}$ & \\
\hline No & 32 & 60.4 & 17 & 53.1 & 15 & 46.9 & & 1 \\
\hline Yes & 21 & 39.6 & 07 & 33.3 & 14 & 66.7 & & $0.44(0.14-1.38)$ \\
\hline Psychiatric hospitalization (previous) & & & & & & & $0.38^{c}$ & \\
\hline No & 35 & 66.0 & 13 & 37.1 & 22 & 62.9 & & 1 \\
\hline Yes & 18 & 34.0 & 11 & 61.1 & 07 & 38.9 & & $2.65(0.82-8.56)$ \\
\hline Tobacco use (lifetime) & & & & & & & $0.10^{c}$ & \\
\hline No & 16 & 30.2 & 10 & 62.5 & 06 & 37.5 & & 1 \\
\hline Yes & 37 & 69.8 & 14 & 37.8 & 23 & 62.2 & & $0.36(0.11-1.22)$ \\
\hline Illicit drug use (lifetime) & & & & & & & $0.50^{c}$ & \\
\hline No & 44 & 83.0 & 17 & 42.5 & 23 & 57.5 & & 1 \\
\hline Yes & 09 & 17.0 & 07 & 53.8 & 06 & 46.2 & & $1.58(0.49-5.55)$ \\
\hline Thought life was not worth living (lifetime) & & & & & & & $0.11^{b}$ & \\
\hline No & 13 & 24.5 & 03 & 23.1 & 10 & 76.9 & & 1 \\
\hline Yes & 40 & 75.5 & 21 & 52.5 & 19 & 47.5 & & $3.68(0.88-15.42)$ \\
\hline Desired to be dead (lifetime) & & & & & & & $0.08^{b}$ & \\
\hline No & 18 & 34.0 & 05 & 27.8 & 13 & 72.2 & & 1 \\
\hline Yes & 35 & 66.0 & 19 & 54.3 & 16 & 45.7 & & $3.09(0.90-10.53)$ \\
\hline Suicidal thoughts (lifetime) & & & & & & & $0.04^{c}$ & \\
\hline No & 22 & 41.5 & 06 & 27.3 & 16 & 72.7 & & 1 \\
\hline Yes & 31 & 58.5 & 18 & 58.1 & 13 & 41.9 & & $3.69(1.14-12.00)$ \\
\hline Suicide plans (lifetime) & & & & & & & $0.02^{c}$ & \\
\hline No & 31 & 58.5 & 09 & 29.0 & 22 & 71.0 & & 1 \\
\hline Yes & 22 & 41.5 & 15 & 68.2 & 07 & 31.8 & & $5.24(1.60-17.15)$ \\
\hline Suicide attempts (lifetime) & & & & & & & $0.02^{c}$ & \\
\hline No & 32 & 60.4 & 10 & 31.2 & 22 & 71.0 & & 1 \\
\hline Yes & 21 & 39.6 & 14 & 66.7 & 07 & 31.8 & & $4.40(1.36-14.25)$ \\
\hline Suicidal thoughts (current) & & & & & & & $0.65^{b}$ & \\
\hline No & 48 & 90.6 & 21 & 43.7 & 27 & 56.3 & & 1 \\
\hline Yes & 05 & 9.4 & 03 & 60.0 & 02 & 40.0 & & $1.92(0.29-12.61)$ \\
\hline Depression (current) & & & & & & & $0.02^{\mathrm{b}}$ & \\
\hline No $(B D I<19)$ & 41 & 77.3 & 15 & 36.6 & 26 & 63.4 & & 1 \\
\hline Yes (BDI $\geq 19)$ & 12 & 22.7 & 09 & 75.0 & 03 & 25.0 & & $5.20(1.22-22.23)$ \\
\hline Moderate/severe dependence (current) & & & & & & & & \\
\hline № $(S A D D<10)$ & 48 & 90.6 & 22 & 45.8 & 26 & 54.2 & $1.00^{\mathrm{b}}$ & 1 \\
\hline Yes $(S A D D \geq 10)$ & 05 & 9.4 & 02 & 40.0 & 03 & 60.0 & & $0.79(0.12-5.15)$ \\
\hline
\end{tabular}

Significant values in bold. SAD: social anxiety disorder; SD: standard deviation; BDI: Beck Depression Inventory; SADD: Short Alcohol Dependence Data.

${ }^{a}$ Mann-Whitney test;; ${ }^{b}$ Fisher's exact test; ${ }^{c}$ Chi-square test. 


\section{Correlates of (general and specific) social anxiety symptoms severity}

The overall SAD severity (SPIN total score) was positively associated with (moderate or severe) depression, BDI score and all lifetime suicidal behaviors, and negatively associated with age and income (Table 3). Social inadequacy score was associated with BDI score, suicidal ideation, suicide plans and attempts, and negatively associated with income. The self-esteem subscale was positively associated with BDI score and negatively with income. Physiological symptoms were positively associated with depression, suicide plans and attempts, $\mathrm{BDI}$ and SADD scores, and negatively associated with age. Social inferiority was positively associated with lifetime death wishes, suicidal ideation, suicide attempts, BDI and SADD scores, and negatively associated with age. Finally, performance when observed by others was positively associated with thinking that life is not worth living, death wishes, BDI score, and negatively associated with age and income (Table 3).

\section{DISCUSSION}

This is the first Brazilian study and one of the few studies in the literature evaluating the prevalence and correlates of SAD symptoms in alcohol-dependent men and women undergoing outpatient treatment for the dependence. The outcome was evaluated using a validated instrument (SPIN) and analyzed both categorically (probable SAD) and dimensionally (severity of social anxiety symptoms). For the first time, the severity and correlates of specific SAD symptoms were investigated in this population. In addition, several explanatory variables were investigated, including suicidal behaviors.

The results indicate that the prevalence of SAD is much higher in individuals with AUD than in the general population $^{39-41}$. The current prevalence was $45.3 \%$ (95\% Cl: 31.4-59.1\%), much higher $(p<0.001)$ than those reported in two Brazilian epidemiological surveys conducted in São Paulo city, with annual rates of $2.2 \%^{6}$ and $3.9 \%$. In community samples from other countries, the annual prevalence ranges from $1.9 \%$ to

Table 3. Associations between total and specific social anxiety symptom scores (SPIN subscales) and explanatory variables

\begin{tabular}{|c|c|c|c|c|c|c|}
\hline $\begin{array}{l}\text { Categorical } \\
\text { Variables* }\end{array}$ & $\begin{array}{l}\text { SPIN } \\
\text { Total } \\
\text { Score }\end{array}$ & $\begin{array}{c}\text { Social } \\
\text { Inadequacy }\end{array}$ & Self-Esteem & Physiological Symptoms & Social Inferiority & $\begin{array}{l}\text { Performance when } \\
\text { observed }\end{array}$ \\
\hline Sex & ns & ns & ns & ns & ns & ns \\
\hline Hospitalization & ns & ns & ns & ns & ns & ns \\
\hline $\begin{array}{l}\text { Depression } \\
(B D I \geq 19)\end{array}$ & $\begin{array}{c}28.5 \text { vs } 17.9 \\
p=0.038\end{array}$ & ns & ns & $\begin{array}{l}7.7 \text { vs } 4.0 \\
p=0.01\end{array}$ & ns & ns \\
\hline $\begin{array}{l}\text { Thought life was not worth } \\
\text { (lifetime) }\end{array}$ & $\begin{array}{l}22.8 \text { vs } 12.6 \\
p=0.044\end{array}$ & ns & ns & ns & ns & $\begin{array}{l}5.7 \text { vs } 3.1 \\
p=0.03\end{array}$ \\
\hline $\begin{array}{l}\text { Desired to be dead } \\
\text { (lifetime) }\end{array}$ & $\begin{array}{c}23.8 \text { vs } 13.7 \\
p=0.028\end{array}$ & ns & ns & ns & $\begin{array}{l}1.2 \text { vs } 0.06 \\
p=0.019\end{array}$ & $\begin{array}{l}5.8 \text { vs } 3.7 \\
p=0.046\end{array}$ \\
\hline Suicidal thoughts (lifetime) & $\begin{array}{c}24.4 \text { vs } 14.6 \\
p=0.045\end{array}$ & $\begin{array}{l}5.0 \text { vs } 2.4 \\
p=0.02\end{array}$ & ns & ns & $\begin{array}{l}1.3 \text { vs } 0.14 \\
p=0.02\end{array}$ & ns \\
\hline $\begin{array}{l}\text { Suicide plans } \\
\text { (lifetime) }\end{array}$ & $\begin{array}{c}26.9 \text { vs } 15.7 \\
p=0.02\end{array}$ & $\begin{array}{l}5.5 \text { v } 2.8 \\
p=0.02\end{array}$ & ns & $\begin{array}{l}6.8 \text { vs } 3.5 \\
p=0.02\end{array}$ & ns & ns \\
\hline Suicide attempts (lifetime) & $\begin{array}{l}27.4 \text { vs } 15.7 \\
p=0.018\end{array}$ & $\begin{array}{l}5.5 \text { vs } 2.9 \\
p=0.03\end{array}$ & ns & $\begin{array}{l}6.7 \text { vs } 3.7 \\
p=0.03\end{array}$ & $\begin{array}{l}1.6 \text { vs } 0.3 \\
p=0.047\end{array}$ & ns \\
\hline Suicidal thoughts (current) & ns & ns & ns & ns & ns & ns \\
\hline $\begin{array}{l}\text { Quantitative } \\
\text { Variables** }\end{array}$ & $\begin{array}{l}\text { SPIN } \\
\text { Total } \\
\text { Score }\end{array}$ & Social Inadequacy & Self-Esteem & Physiological Symptoms & Social Inferiority & $\begin{array}{c}\text { Performance when } \\
\text { observed }\end{array}$ \\
\hline Age (years) & $\begin{array}{l}r=-0.33 \\
p=0.015\end{array}$ & ns & ns & $\begin{array}{l}r=-0.33 \\
p=0.016\end{array}$ & $\begin{array}{l}r=-0.28 \\
p=0.04\end{array}$ & $\begin{array}{l}r=-0.35 \\
p=0.01\end{array}$ \\
\hline Income (Brazilian real) & $\begin{array}{l}r=-0.35 \\
p=0.01\end{array}$ & $\begin{array}{l}r=-0.34 \\
p=0.01\end{array}$ & $\begin{array}{l}r=-0.35 \\
p=0.01\end{array}$ & ns & ns & $\begin{array}{l}r=-0.31 \\
p=0.026\end{array}$ \\
\hline BDIscore & $\begin{array}{l}r=0.42 \\
p=0.002\end{array}$ & $\begin{array}{l}r=0.40 \\
p=0.003\end{array}$ & $\begin{array}{l}r=0.29 \\
p=0.03\end{array}$ & $\begin{aligned} r & =0.48 \\
p & <0.001\end{aligned}$ & $\begin{array}{l}r=0.33 \\
p=0.017\end{array}$ & $\begin{array}{l}r=0.27 \\
p=0.047\end{array}$ \\
\hline SADD score & ns & ns & ns & $\begin{array}{c}r=0.27 \\
p=0.047\end{array}$ & $\begin{array}{l}r=0.29 \\
p=0.03\end{array}$ & ns \\
\hline
\end{tabular}

Significant results in bold.

* Mann Whitney test (mean scores in the 'SAD' group versus 'Non-SAD' group); ** Spearman's correlation test.

BDI: Beck Depression Inventory; SADD: Short Alcohol Dependence Data; ns: non-significant. 
$6.8 \% \%^{2,4}$ and the lifetime prevalence from $2.8 \%$ to $12.0 \% \%^{23,5,6}$. In studies with hospitalized alcohol-dependent patients, it ranges from $25 \%{ }^{19}$ to $35 \%^{20}$. This difference may be partly explained by methodological issues (e.g. diagnostic criteria, assessment instruments) or by the fact that patients attended at a tertiary service may present more comorbidities. According to Buckner et al. ${ }^{13}$, however, approximately half of alcohol-dependent patients seeking detoxification present moderate or severe social anxiety symptoms.

Since alcohol addiction develops gradually over several years, preceded by a variable period of harmful alcohol use, the delay in treatment seeking is the rule ${ }^{42}$. In this study, the average interval between the beginning of alcohol use and the diagnosis and treatment of alcohol dependence was 30 years. However, the mean ages of onset of alcohol use, and of alcohol dependence diagnosis and treatment did not differ between the study groups. Although the SAD group had a lower mean age (46 vs. 52 years old), this difference did not reach statistical significance. Thus, population-based studies are needed to evaluate whether SAD comorbidity affects (decreasing or increasing, anticipating or delaying) treatment seeking for alcohol dependence. Nevertheless, in a sample of substance abusers, those with clinically relevant SAD symptoms were 4-8 times more likely to report that shyness interfered with addiction treatment activities ${ }^{22}$. The group format, which is frequently used in therapeutic programs for alcohol-dependent patients - and used in our service - is an additional barrier for persons with AUD and SAD symptoms to seek or adhere to treatment ${ }^{22}$.

Anxiety disorders can be cause or consequence of alcohol dependence and common etiological factors can also be involved, but usually social anxiety symptoms precede alcohol dependence by several years ${ }^{43-46}$. In fact, SAD usually begins in childhood or early adolescence ${ }^{1}$ and some individuals may use alcohol as "self-medication" to try to alleviate SAD symptoms and improve sociability ${ }^{18}$, gradually becoming dependent $t^{43-50}$. Although almost $40 \%$ of the patients reported that SAD symptoms decreased with alcohol use, the cross-sectional design does not permit causality inferences. Since anxiety manifestations (e.g. tremors, sweating, increased heart rate) are common during alcohol withdrawal syndrome ${ }^{42}$, SAD can go even more unnoticed and untreated in this population.

The sample was composed predominantly by male patients (69.8\%), as consistently described in community and clinical studies on substance use ${ }^{2}$, but men and women did not differ significantly regarding the prevalence of SAD. In fact, the only sociodemographic variable that differed between the two study groups was income, in average lower in patients with SAD. The worse socioeconomic status of patients with SAD may be due to additional difficulties - beyond the effect of alcohol dependence - in adapting to the work environment ${ }^{23,51}$.
High tobacco smoking rate was expected ${ }^{52}$ and confirmed in the sample as a whole (70\%), but the two groups did not differ in this respect. The use of illicit drugs was much less common, but also similar in patients with and without SAD.

Anxiety disorders in general may contribute to the maintenance and relapse of AUD $8,12,45$ and comorbidity of AUD can be an indicator of more severe $\mathrm{SAD}^{50,53,54}$, with more suicidal behaviors ${ }^{8,55,56}$. In anxiety disorders, the co-occurrence of comorbidities, such as depression, is associated with greater severity, disability and poorer treatment response ${ }^{13,57}$. As expected, in this sample, patients with SAD were more likely than non-SAD patients to present moderate or severe depression (37.5\% vs 10.3\%; $p=0.02$ ). Likewise, the $B D I$ score was much higher in the SAD group (18.4 vs $7.3 ; p<0.001)^{18}$.

Suicidal behaviors were frequently observed in the total sample, and lifetime suicidal ideation, suicide plans and attempts were more common in alcohol-dependent patients with SAD. Thus, the SAD comorbidity seems to further increase the frequency of suicidal behaviors in these patient $5^{58-63}$. Interestingly, Bolton et al. ${ }^{64}$ conducted a study with 8,098 individuals from the US general population and reported that those who used alcohol as self-medication in an attempt to inhibit SAD symptoms presented increased suicide risk, compared with those who did not drink (23.7\% vs 6.2\%). The co-occurrence of SAD and depressive disorder is common and associated with additional suffering, social dysfunction and suicidal ideation ${ }^{8,65}$. According to Bunevicius et al. ${ }^{66}$, there is an important relationship between suicidal ideation, excessive alcohol consumption and depressive episodes. The cross-sectional design does not allow conclusions on direction of causality but, as already mentioned, SAD symptoms usually precede not only alcohol harmful use $e^{43-48}$, but also depressive symptoms $s^{67,68}$. Thus, SAD probably represents the beginning of a series of psychopathological manifestations that develop in a causal pathway to suicidal behaviors ${ }^{69}$. In this case, depression and/or alcohol dependence are not confounders, but mediating factors of the association between SAD symptoms and suicidality.

In fact, the association between anxiety symptoms/disorders and suicidality has been consistently described in the literature ${ }^{56,69-72}$. Self-reported anxiety symptoms increased by 2 -fold the likelihood of reporting suicidal behaviors among 2,778 psychiatric outpatients ${ }^{71}$. In a systematic review and meta-analysis of 42 observational studies, Kanwar et al. ${ }^{70}$ concluded that, compared to patients without anxiety, those with anxiety disorders were more likely to have suicidal ideations $(O R=2.89)$, attempted suicides $(O R=2.47)$ and completed suicides $(O R=3.34)$. In an important study by Cougle et al. using data from the National Comorbidity Survey Replication, anxiety disorders - including SAD - were independent predictors of suicidal ideation and suicide attempts ${ }^{56}$. Moreover, the role of anxiety symptoms and disorders in the incidence of depression and suicidal behaviors has been 
demonstrated in community-based longitudinal studies ${ }^{69,72}$. Notably, a recent review on addiction and suicide ${ }^{73}$ emphasizes that suicidality is indeed a relevant problem for people with co-occurring psychiatric disorders (major depression, schizophrenia, PTSD and personality disorders) seeking addiction treatment, but anxiety disorders are not cited. Therefore, more attention should be given by researchers and clinicians to anxiety disorders comorbidity regarding additional suicide risk in patients with substance use disorders.

Since non-fatal suicidal behaviors usually precede more serious and even fatal behaviors ${ }^{58,74,75}$, the active investigation of SAD symptoms in this population is an important opportunity for prevention. With regard to suicide risk, health professionals should be particularly careful with alcoholdependent patients who present more severe symptoms of social inadequacy and social inferiority. Nevertheless, more studies are needed to confirm or refute the importance of specific SAD symptoms to suicide risk in this population.

\section{Limitations}

The cross-sectional design does not allow inferences about cause and effect, but just indicates associations between the outcome and explanatory variables. The instruments assessed current psychopathological symptoms and did not include questions on age of onset of the disorders (SAD, depression); only age at onset of alcohol use was investigated. The small sample size probably limited the study power and the sample was not probabilistic. Despite being a validated instrument in our country, the SPIN is not a diagnostic tool, and the SAD diagnosis was determined with its threshold score and not with a clinical diagnostic interview. Likewise, the $\mathrm{BDI}$ evaluates depressive symptoms, but it is not a diagnostic instrument. Depressive cognitive biases may have influenced the answers to the SPIN, since BDI and SPIN scores were correlated. Data was collected in a tertiary outpatient service; therefore, the generalization of the results to alcohol-dependent individuals in the community or patients attended at primary or secondary health services should be made with caution. Suicidality is a very complex phenomenon and other relevant risk factors - e.g. stressful life events, marital conflicts, family history of suicide, organic diseases and personality disorders - were not investigated.

\section{CONCLUSIONS}

The prevalence of symptoms suggestive of SAD among alcohol-dependent outpatients was very high (45.3\%), much higher than the prevalence rates reported in community studies. Compared with non-SAD alcohol-dependent patients, patients with SAD had lower income, more frequent and severe depressive symptoms, and more suicidal behaviors. Social inadequacy and social inferiority were the $S A D$ manifestations mostly associated with suicidality in this treatment-seeking sample of alcohol-dependent individuals.

Since SAD symptoms can go unnoticed and negatively impact the clinical course and prognosis of alcohol dependence, it is essential to directly investigate and properly treat these symptoms in clinical samples of alcohol-dependent patients. Community-based studies on the influence of SAD symptoms in help-seeking behaviors for alcohol dependence are warranted.

More clinical studies (with larger samples, other types of services, investigating other independent variables and using prospective designs) are needed to better understand the impact of SAD comorbidity on the alcohol dependence prognosis, including relapses and suicide risk. Intervention studies examining the effect of specific pharmacological and psychotherapeutic strategies for SAD symptoms on the clinical course of alcohol dependence are also much necessary.

\section{INDIVIDUAL CONTRIBUTIONS}

Nicoli Tamie Yoshimi - Study planning, data collection, dataset organization, literature review, interpretation of data, first draft and final version of the manuscript.

Luana Moraes Campos - Data collection and dataset organization, preparation of the final version of the manuscript.

Maria Odete Simão - Planning, organization and supervision of data collection, dataset organization.

Ricardo Cezar Torresan - Study design and planning, assistance in literature review, and interpretation of data.

Albina Rodrigues Torres - Study design and planning, statistical analysis, interpretation of data and preparation of the first draft and final version of the manuscript.

\section{CONFLICTS OF INTEREST}

The authors have no conflicts of interest to declare.

\section{ACKNOWLEDGEMENTS}

The authors are grateful to the patients that participated in this study and to the National Council for Scientific and Technological Development (CNPq - Institutional Program for Undergraduate Research Grants, Pibic), Brazil, for the one-year scholarship granted to the medical students NTY and LMC.

\section{REFERENCES}

1. American Psychiatric Association. Diagnostic and statistical manual of mental disorders (DSM-5). 5th ed. Washington, DC: American Psychiatric Association; 2013. 
2. Saban A, Flisher AJ, Grimsrud A, Morojele N, London L, Williams DR, et al. The association between substance use and common mental disorders in young adults: results from the South African Stress and Health (SASH) Survey. Pan Afr Med J. 2014;17 Suppl 1:11.

3. Grant BF, Hasin DS, Blanco C, Stinson FS, Chou SP, Goldstein RB, et al. The epidemiology of social anxiety disorder in the United States: results from the National Epidemiologic Survey on Alcohol and Related Conditions. J Clin Psychiatry. 2005;66(11):1351-61.

4. Kessler RC, Chiu WT, Demler 0, Merikangas KR, Walters EE. Prevalence, severity, and comorbidity of 12-month DSM-IV disorders in the National Comorbidity Survey Replication. Arch Gen Psychiatry. 2005;62(6):617-27.

5. Kessler RC, Berglund P, Demler 0 , Jin R, Merikangas KR, Walters EE. Lifetime prevalence and age-of-onset distributions of DSM-IV disorders in the National Comorbidity Survey Replication. Arch Gen Psychiatry. 2005;62(6):593-602.

6. Andrade L, Walters EE, Gentil V, Laurenti R. Prevalence of ICD-10 mental disorders in a catchment area in the city of São Paulo, Brazil. Soc Psychiatry Psychiatr Epidemiol. 2002;37(7):316-25

7. Andrade LH, Baptista MC, Alonso J, Petukhova M, Bruffaerts R, Kessler RC, et al. Days outof-role due to common physical and mental health problems: results from the São Paulo Megacity Mental Health Survey, Brazil. Clinics (Sao Paulo). 2013;68(11):1392-9.

8. Grant BF, Stinson FS, Dawson DA, Chou SP, Dufour MC, Compton W, et al. Prevalence and co-occurrence of substance use disorders and independent mood and anxiety disorders: results from the National Epidemiologic Survey on Alcohol and Related Conditions. Arch Gen Psychiatry. 2004;61(8):807-16.

9. Morris EP, Stewart SH, Ham LS. The relationship between social anxiety disorder and alcohol use disorders: a critical review. Clin Psychol Rev. 2005;25(6):734-60.

10. Schneier FR, Foose TE, Hasin DS, Heimberg RG, Liu SM, Grant BF, et al. Social anxiety disorder and alcohol use disorder co-morbidity in the National Epidemiologic Survey on Alcohol and Related Conditions. Psychol Med. 2010;40(6):977-88.

11. Marmorstein NR. Anxiety disorders and substance use disorders: different associations by anxiety disorder. J Anxiety Disord. 2012;26(1):88-94.

12. Crum RM, La Flair L, Storr CL, Green KM, Stuart EA, Alvanzo AA, et al. Reports of drinking to self-medicate anxiety symptoms: longitudinal assessment for subgroups of individuals with alcohol dependence. Depress Anxiety. 2013;30(2):174-83.

13. Buckner JD, Heimberg RG, Ecker AH, Vinci C. A biopsychosocial model of social anxiety and substance use. Depress Anxiety. 2013;30(3):276-84

14. Book SW, Randall CL. Social anxiety disorder and alcohol use. Alcohol Res Health. 2002;26(2):130-5.

15. Terra MB, Barros HM, Stein AT, Figueira I, Jorge MR, Palermo LH, et al. Social anxiety disorder in 300 patients hospitalized for alcoholism in Brazil: high prevalence and undertreatment. Compr Psychiatry. 2006;47(6):463-7.

16. Olgiati P, Liappas I, Malitas P, Piperi C, Politis A, Tzavellas E0, et al. Depression and social phobia secondary to alcohol dependence. Neuropsychobiology. 2007;56(2-3):111-8.

17. McGovern MP, Xie H, Segal SR, Siembab L, Drake RE. Addiction treatment services and co-occurring disorders: Prevalence estimates, treatment practices, and barriers. J Subst Abuse Treat. 2006;31(3):267-75.

18. Thomas SE, Thevos AK, Randall CL. Alcoholics with and without social phobia: a comparison of substance use and psychiatric variables. I Stud Alcohol. 1999;60(4):472-9.

19. Lydiard RB, Brady K, Ballenger JC, Howell EF, Malcolm R. Anxiety and mood disorders in hospitalized alcoholic individuals. Am J Addictions. 1992;1(4):325-31.

20. Bittencourt SA, Oliveira MS, Souza CS. Estudo de relações entre fobia social e uso do álcool. Rev Bras Ter Cogn. 2005;1(2):135-46

21. Adamson SJ, Todd FC, Sellman JD, Huriwai T, Porter J. Coexisting psychiatric disorders in a New Zealand outpatient alcohol and other drug clinical population. Aust N Z J Psychiatry. 2006:40(2):164-70

22. Book SW, Thomas SE, Dempsey JP, Randall PK, Randall CL. Social anxiety impacts willingness to participate in addiction treatment. Addict Behav. 2009;34(5):474-6.

23. Thevos AK, Thomas SE, Randall CL. Baseline differences in social support among treatment-seeking alcoholics with and without social phobia. Subst Abus. 1999;20(2):107-18.

24. Terlecki MA, Buckner JD, Larimer ME, Copeland AL. The role of social anxiety in a brief alcohol intervention for heavy drinking college students. J Cogn Psychother. 2011;25(1):7-21.
25. American Psychiatric Association. Diagnostic and Statistical Manual of Mental Disorders (DSM-IV). 4th ed. Washington, DC: American Psychiatric Association; 1994.

26. Lewis G, Pelosi AJ. Manual of the Revised Clinical Interview Schedule CIS-R. London: Institute of Psychiatry; 1990.

27. Lewis G, Pelosi AJ, Araya R, Dunn G. Measuring psychiatric disorder in the community: a standardized assessment for use by lay interviewers. Psychol Med. 1992;22(2):465-86.

28. Connor KM, Davidson JR, Churchill LE, Sherwood A, Foa E, Weisler RH. Psychometric properties of the Social Phobia Inventory (SPIN). New self-rating scale. Br J Psychiatry. 2000;176:379-86.

29. Osório FL, Crippa JAS, Zuardi AW, Graeff FG, Busatto G, Pinho M, et al. Inventário de Fobia Social (SPIN): validação para o Brasil. Rev Bras Psiquiatr. 2004;26(Supl 2):S6.

30. Osório FL, Crippa JAS, Loureiro SR. Cross- cultural validation of the Brazilian Portuguese version of the Social Phobia Inventory (SPIN): study of the items and internal consistency. Rev Bras Psiquiatr. 2009;31(1):25-9.

31. Vilete LMP, Coutinho ESF, Figueira ILV. Confiabilidade da versão em Português do Inventário de Fobia Social (SPIN) entre adolescentes estudantes do Município do Rio de Janeiro. Cad Saude Publica. 2004;20(1):89-99.

32. Fernandes GC, Terra MB. Fobia social: estudo da prevalência em duas escolas em Porto Alegre. J Bras Psiquiatr. 2008;57(2):122-6

33. D'El Rey GJF, Pacini CA, Chavira DJF. Fobia social em uma amostra de adolescentes. Estud Psicol (Natal). 2006;11(1):111-4

34. Raistrick D, Dunbar G, Davidson R. Development of a questionnaire to measure alcohol dependence. Br J Addict. 1983;78(1):89-95.

35. Davidson R, Raistrick D. The validity the Short-Form Alcohol Dependence Data (SADD) Questionnaire: a short self-report questionnaire for an assessment of alcohol dependence. Br J Addict. 1985;81:217-22.

36. Jorge MR, Masur J. Questionários padronizados para avaliação do grau de severidade da síndrome de dependência do álcool. J Bras Psiquiatr. 1986;35:287-92.

37. Beck AT, Ward CH, Mendelson M, Mock J, Erbaugh J. An inventory for measuring depression. Arch Gen Psychiatry. 1961;4:561-71.

38. Stata Corporation. 2011. Stata Statistical Software. Release 12.0. College Station, TX: Stata Corporation.

39. Terra MB, Figueira I, Barros HM. Impact of alcohol intoxication and withdrawal syndrome on social phobia and panic disorder in alcoholic inpatients. Rev Hosp Clin Fac Med Sao Paul0. 2004:59(4):187-92.

40. Brady KT, Haynes LF, Hartwell KJ, Killeen TK. Substance use disorders and anxiety: a treatment challenge for social workers. Soc Work Public Health. 2013;28(3-4):407-23.

41. Tomlinson KL, Cummins KM, Brown SA. Social anxiety and onset of drinking in early adolescence. J Child Adolesc Subst Abuse. 2013;22(2):163-77.

42. Schuckit MA, Irwin M, Brown SA. The history of anxiety symptoms among 171 primary alcoholics. J Stud Alcohol. 1990;51(1):34-41.

43. Kushner MG, Sher KJ, Beitman BD. The relation between alcohol problems and the anxiety disorders. Am J Psychiatry. 1990;147(6):685-95.

44. Kushner MG, Sher KJ, Erickson DJ. Prospective analysis of the relation between DSM-III anxiety disorders and alcohol use disorders. Am J Psychiatry. 1999;156(5):723-32.

45. Kushner MG, Abrams K, Borchardt C. The relationship between anxiety disorders and alcohol use disorders: a review of major perspectives and findings. Clin Psychol Rev. 2000;20(2):149-71.

46. Merikangas KR, Mehta RL, Molnar BE, Walters EE, Swendsen JD, Aguilar-Gaziola S, et al. Comorbidity of substance use disorders with mood and anxiety disorders: results of the International Consortium in Psychiatric Epidemiology. Addict Behav. 1998;23(6):893-907.

47. Beesdo K, Bittner A, Pine DS, Stein MB, Höfler M, Lieb R, et al. Incidence of social anxiety disorder and the consistent risk for secondary depression in the first three decades of life. Arch Gen Psychiatry. 2007;64(8):903-12.

48. Buckner JD, Schmidt NB. Understanding social anxiety as a risk for alcohol use disorders: fear of scrutiny, not social interaction fears, prospectively predicts alcohol use disorders. J Psychiatr Res. 2009;43(4):477-83.

49. Zimmermann P, Wittchen HU, Höfler M, Pfister H, Kessler RC, Lieb R. Primary anxiety disorders and the development of subsequent alcohol use disorders: a 4-year community study of adolescents and young adults. Psychol Med. 2003;33(7):1211-22. 
50. Robinson J, Sareen J, Cox BJ, Bolton J. Self-medication of anxiety disorders with al cohol and drugs: Results from a nationally representative sample. J Anxiety Disord. 2009;23(1):38-45.

51. Katzelnick DJ, Kobak KA, DeLeire T, Henk HJ, Greist JH, Davidson JR, et al. Impact of generalized social anxiety disorder in managed care. Am J Psychiatry. 2001;158(12):1999-2007.

52. Grant BF, Hasin DS, Chou SP, Stinson FS, Dawson DA. Nicotine dependence and psychiatric disorders in the United States: results from the national epidemiologic survey on alcohol and related conditions. Arch Gen Psychiatry. 2004;61(11):1107-15.

53. Smail P, Stockwell T, Canter S, Hodgson R. Alcohol dependence and phobic anxiety states. I. A prevalence study. Br J Psychiatry. 1984;144:53-7.

54. Carrigan MH, Randall CL. Self-medication in social phobia: a review of the alcohol literature. Addict Behav. 2003;28(2):269-84.

55. Cox BJ, Direnfeld DM, Swinson RP, Norton GR. Suicidal ideation and suicide attempts in panic disorder and social phobia. Am J Psychiatry. 1994;151(6):882-7.

56. Cougle JR, Keough ME, Riccardi CJ, Sachs-Ericsson N. Anxiety disorders and suicidality in the National Comorbidity Survey-Replication. J Psychiatr Res. 2009;43(9):825-9.

57. Howland RH, Rush AJ, Wisniewski SR, Trivedi MH, Warden D, Fava M, et al. Concurrent anxiety and substance use disorders among outpatients with major depression: clinical features and effect on treatment outcome. Drug Alcohol Depend. 2009;99(1-3):248-60.

58. Borges G, Walters EE, Kessler RC. Associations of substance use, abuse, and dependence with subsequent suicidal behavior. Am J Epidemiol. 2000;151(8):781-9.

59. Bertolote JM, Fleischmann A. Suicide and psychiatric diagnosis: a worldwide perspective. World Psychiatry. 2002;1(3):181-5.

60. Cavanagh JT, Carson AJ, Sharpe M, Lawrie SM. Psychological autopsy studies of suicide: a systematic review. Psychol Med. 2003;33(3):395-405.

61. Wilcox HC, Conner KR, Caine ED. Association of al cohol and drug use disorders and completed suicide: an empirical review of cohort studies. Drug Alcohol Depend. 2004;76 Suppl:S11-9.

62. Sher L. Alcoholism and suicidal behavior: a clinical overview. Acta Psychiatr Scand. 2006;113(1):13-22

63. Boenisch S, Bramesfeld A, Mergl R, Havers I, Althaus D, Lehfeld H, et al. The role of alcohol use disorder and alcohol consumption in suicide attempts - a secondary analysis of 1921 suicide attempts. Eur Psychiatry. 2010;25(7):414-20.
64. Bolton J, Cox B, Clara I, Sareen J. Use of alcohol and drugs to self-medicate anxiety disorders in a nationally representative sample. J Nerv Ment Dis. 2006;194(11):818-25.

65. Joormann J, Kosfelder J, Schulte D. The impact of comorbidity of depression on the course of anxiety treatments. Cogn Ther Res. 2005;29(5):569-91.

66. Bunevicius R, Liaugaudaite V, Peceliuniene J, Raskauskiene N, Bunevicius A, Mickuviene N. Factors affecting the presence of depression, anxiety disorders, and suicidal ideation in patients attending primary health care service in Lithuania. Scand J Prim Health Care. 2014;32(1):24-9.

67. Dalrymple KL, Zimmerman M. Age of onset of social anxiety disorder in depressed outpatients. J Anxiety Disord. 2011;25(1):131-7.

68. Tsuchiya M, Kawakami N, Ono Y, Nakane Y, Nakamura Y, Tachimori H, et al. Lifetime comorbidities between phobic disorders and major depression in Japan: results from the World Mental Health Japan 2002-2004 Survey. Depress Anxiety. 2009;26(10):949-55.

69. Batterham PJ, Christensen H, Calear AL. Anxiety symptoms as precursors of major depression and suicidal ideation. Depress Anxiety. 2013;30(10):908-16.

70. Kanwar A, Malik S, Prokop LJ, Sim LA, Feldstein D, Wang Z, et al. The association between anxiety disorders and suicidal behaviors: a systematic review and meta-analysis. Depress Anxiety. 2013;30(10):917-29.

71. Diefenbach GJ, Woolley SB, Goethe JW. The association between self-reported anxiety symptoms and suicidality. J Nerv Ment Dis. 2009;197(2):92-7.

72. Sareen J, Cox BJ, Afifi TO, de Graaf R, Asmundson GJ, ten Have M, et al. Anxiety disorders and risk for suicidal ideation and suicide attempts: a population-based longitudinal study of adults. Arch Gen Psychiatry. 2005;62(11):1249-57.

73. Yuodelis-Flores C, Ries RK. Addiction and suicide: a review. Am J Addict. 2015;24(2):98104.

74. Lee S, Fung SC, Tsang A, Liu ZR, Huang YQ, He YL, et al. Lifetime prevalence of suicide ideation, plan, and attempt in metropolitan China. Acta Psychiatr Scand. 2007;116(6):429-37.

75. Scocco P, de Girolamo G, Vilagut G, Alonso J. Prevalence of suicide ideation, plans and attempts and related risk factors in Italy: Results from the European Study on the Epidemiology of Mental Disorders - World Mental Health study. Compr Psychiatry. 2008;:49:13-21. 